\title{
REVIEW
}

\section{Post-transcriptional gene regulatory mechanisms in eukaryotes: an overview}

\author{
D A Day and M F Tuite \\ Department of Biosciences, University of Kent, Canterbury CT2 7NJ, UK \\ (Requests for offprints should be addressed to M F Tuite)
}

\begin{abstract}
Expression of a gene can be controlled at many levels, including transcription, mRNA splicing, mRNA stability, translation and post-translational events such as protein stability and modification. The majority of studies to date have focused on transcriptional control mechanisms, but the importance of post-transcriptional mechanisms in regulating gene expression in eukaryotes is becoming increasingly clear. In this short review, selected examples of post-transcriptional gene regulatory mechanisms operating in both lower and higher eukaryotes will be used to highlight the plethora of such mechanisms already ident-
\end{abstract}

ified. The underlying theme is that post-transciptional gene regulation relies on specific RNA-protein interactions that either result in the targeted degradation of the mRNA or prevent access of the ribosome to the translation start codon. Such interactions can occur in the $5^{\prime}$ or $3^{\prime}$ untranslated regions of an mRNA or within the decoded portion of the molecule. The importance of these regulatory mechanisms in a range of biological systems is also illustrated.

Journal of Endocrinology (1998) 157, 361-371

\section{Introduction}

Translation in eukaryotes is a complex series of steps involving a wide array of protein translation factors that function in conjunction with the ribosome and tRNAs to decode an mRNA, thereby generating the encoded polypeptide chain (reviewed by Merrick \& Hershey 1996). The translation process can be divided into three distinct stages (Fig. 1): (i) initiation, which involves the assembly of the ribosomal subunits at the initiation (AUG) codon of an mRNA (reviewed by Pain 1996); (ii) elongation, the process of tRNA-mediated decoding of the mRNA to form a polypeptide chain (reviewed by Merrick \& Hershey 1996); (iii) termination, during which a stop codon (UAA, UAG or UGA) signals the release of the polypeptide chain from the ribosome and the subsequent dissociation of the ribosomal subunits from the mRNA (reviewed by Stansfield et al. 1995). Each of these stages requires a specific class of translation factor: initiation (eIF), elongation (eEF) and termination (eRF) factors.

The primary target for translational control is at the initiation step, and global regulation of translational initiation can be achieved by post-translational modification of one or more of the initiation factors. Control of translation initiation on individual mRNAs is determined primarily by the structural properties of the mRNA, particularly the $5^{\prime}$ untranslated region (5' UTR). However, features of the $3^{\prime}$ untranslated region ( $3^{\prime}$ UTR), the coding region and interactions between the $5^{\prime}$ and $3^{\prime}$ UTRs of the mRNA also can have profound effects on control. This review will examine the control and regulation of gene expression of post-transcriptional processes in eukaryotic cells, using examples both from simple eukaryotes (especially the yeast Saccharomyces cerevisiae) and from more complex mammalian cells, in order to illustrate the range of regulatory mechanisms already described.

\section{mRNA stability}

The rate of mRNA synthesis is not the sole determinant of the steady-state levels of an mRNA; the mRNA decay rate (i.e. its chemical half-life) is also a major determinant. The half-life of individual mRNAs within a given eukaryotic cell may vary by several orders of magnitude, from a few minutes to many hours and, in some cases, to days. The vast majority of eukaryotic mRNAs carry a $5^{\prime}$ 7-methylguanosine cap structure and a $3^{\prime}$ poly(A) tail of up to 200 adenosine residues in length, which protect the RNA chain from degradation by $5^{\prime} \rightarrow 3^{\prime}$ or $3^{\prime} \rightarrow 5^{\prime}$ 


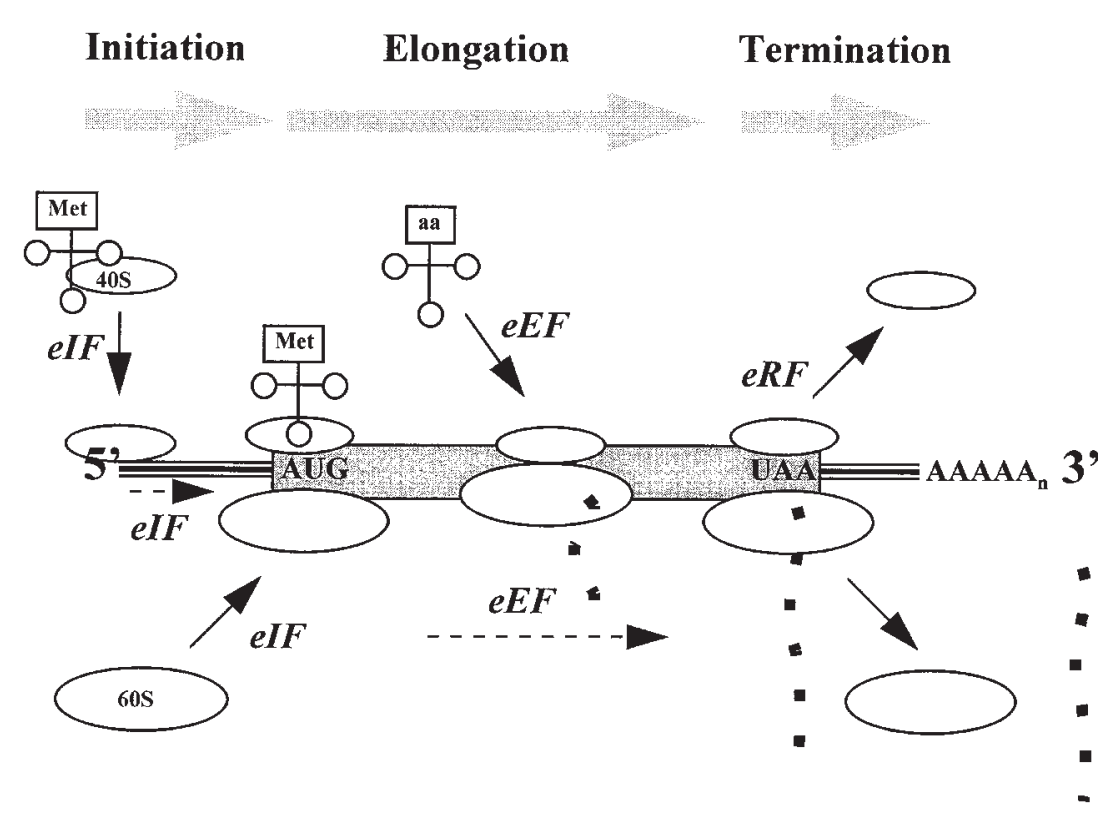

Figure 1 An overview of the three stages of translation in eukaryotic cells. The steps in which the initiation (eIF), elongation (eEF) and termination (eRF) factors have a role are indicated. The steps that involve the movement of the ribosome or ribosomal subunits along the mRNA are indicated by the dashed lines.

exonucleases, or both. In addition to the $5^{\prime}$ cap structure and $3^{\prime}$ poly(A) tail with its associated poly(A)-binding protein $(\mathrm{PABP})$, the intrinsic stability of a given mRNA is also influenced by specific internal sequence elements. A number of such determinants have been identified that exert a destabilising effect on an mRNA and may be located in any region of the transcript. In the mRNAs of the yeast $S$. cerevisiae, for example, such determinants have been found in the $5^{\prime}$ UTR (Pierrat et al. 1993), in the coding region (Herrick \& Jacobson 1992) and in the $3^{\prime}$ UTR (Muhlrad \& Parker 1992) of different mRNAs. In contrast, the existence of stabilising elements in yeast mRNAs is poorly documented.

There are several different mechanisms of eukaryotic mRNA decay (recently reviewed by Jacobson \& Peltz 1996, Ross 1996). A major mRNA decay pathway is initiated by shortening of the poly(A) tail, followed by decapping and subsequent $5^{\prime} \rightarrow 3^{\prime}$ exonucleolytic degradation of the mRNA. A variation of this pathway occurs in which transcripts undergo $3^{\prime} \rightarrow 5^{\prime}$ exonucleolytic decay subsequent to poly(A) shortening. Several sequence elements that promote rapid poly(A) shortening have been identified: for example, sequences within the mammalian c-fos coding region and $3^{\prime}$ UTR contain an AU-rich element (ARE) (Chen et al. 1994) and, in yeast, sequences within the $3^{\prime}$ UTR of the MFA2 mRNA (Muhlrad \& Parker 1992) each appear to function to promote poly(A) shortening. A large number of unstable mammalian mRNAs (including proto-oncogene, transcription factor, cytokine and lymphokine mRNAs) have AREs in their 3'
UTRs (Shaw \& Kamen 1986, Fig. 2a). When the ARE elements from unstable mRNAs (such as c-fos or granulocyte-macrophage colony stimulating factor, GMCSF) are placed within the 3' UTR of a stable mRNA (such as $\beta$-globin), then the normally stable transcript is destabilised (Shaw \& Kamen 1986). Furthermore, a family of ARE-binding proteins (such as AUF1) bind to AREs on many mRNAs and regulate their stability (Ross 1996).

mRNA decay can also be initiated by deadenylationindependent decapping and subsequent $5^{\prime} \rightarrow 3^{\prime}$ decay of the transcript. An example of this process can be found in the degradation of the yeast PGK1 mRNA, which has had a premature nonsense codon introduced by site-directed mutagenesis at the $5^{\prime}$ end of its coding region (Muhlrad \& Parker 1994). The resulting premature translation termination accelerates decay of the transcript (Peltz et al. 1993) and is dependent on trans-acting proteins encoded by the UPF genes (Leeds et al. 1992, Peltz et al. 1994). An analogous mechanism also appears to operate in mammalian cells, and is used to degrade incorrectly processed, intron-containing mRNAs that leave the nucleus (reviewed by Jacobson \& Peltz 1996). Thus eukaryotic cells have evolved a mechanism for degrading aberrant mRNAs that cannot be translated.

There are also examples of eukaryotic mRNAs that can be degraded via endonucleolytic cleavage before deadenylation. Endonuclease cleavage sites have been identified within the coding sequence and the $3^{\prime}$ UTR of several mRNAs. Those within coding regions include mammalian proto-oncogene c-myc mRNA (Bernstein 
$\boldsymbol{a}$

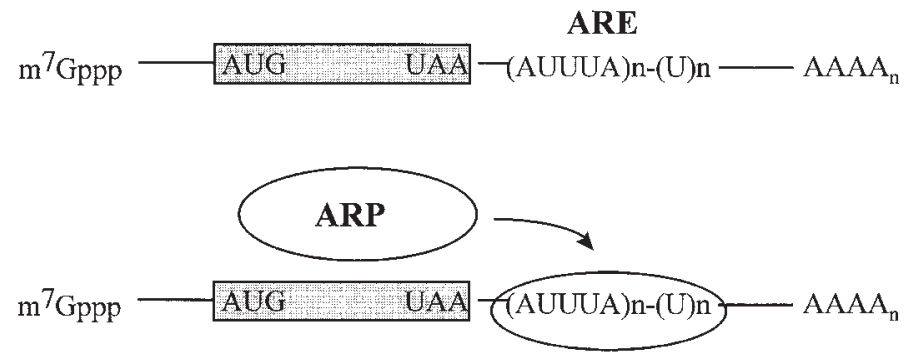

$\boldsymbol{b}$

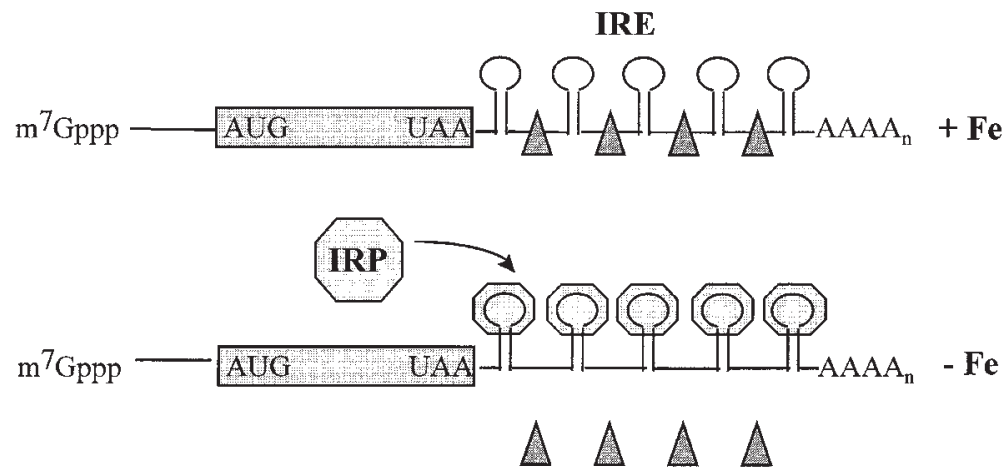

Figure 2 RNA-binding proteins that regulate mRNA stability. (a) A large number of unstable mammalian mRNAs contain AREs in their $3^{\prime}$ untranslated regions ( $3^{\prime}$ UTR), and may be bound by regulatory proteins (ARE-binding proteins, ARP), which promote poly(A) tail shortening. (b) The transferrin receptor (TfR) mRNA contains five IREs and a functional cleavage site within its 3' UTR ( $\mathbf{\Delta})$. In response to low intracellular concentrations of iron, the IRP has a high affinity for the IREs and prevents access of the nuclease to the cleavage sites. Thus binding by the IRP stabilises the transcript by preventing endonucleolytic cleavage.

et al. 1992) and Xenopus laevis albumin mRNA (Dompenciel et al. 1995), and those within a 3' UTR include the mammalian transferrin receptor (TfR; Binder et al. 1994). Endonucleolytic cleavage of some mRNAs is regulated by RNA-binding proteins that bind in the vicinity of the cleavage site(s) and render them inaccessible to nucleolytic attack. In the TfR mRNA, five ironresponse elements (IREs) are located within the 3' UTR and a functional cleavage site is situated between each of the IREs (Fig. 2b). In response to a decrease in intracellular iron concentrations, the IRE binding protein (IREBP, also called the iron regulatory protein, IRP) has a higher affinity for the IREs and, by binding, prevents access of the nuclease to the cleavage site. When iron concentrations are increased, the IRE-IREBP interaction is diminished and endonucleolytic cleavage occurs (Binder et al. 1994).

In summary, the stability of a given mRNA can be controlled by specific intrinsic nucleotide sequences and globally regulated by RNA-binding proteins that bind many mRNAs or are mRNA-specific. Furthermore, the half-life of many mRNAs can fluctuate in response to developmental or environmental stimuli such as nutrient levels, cytokines, hormones, temperature shifts and viral infection.

\section{Regulation of translation initiation}

Translation initiation is an important step in both global and mRNA-specific gene regulation. Global regulation of protein synthesis is generally achieved by the modification of eukaryotic initiation factors (eIFs), several of which (e.g. eIF4E and eIF2; see below) are phosphoproteins. Translational control of individual mRNAs often depends upon the structural features of the transcript itself, and may include structures in the $5^{\prime}$ UTR that inhibit initiation directly, for example by impeding $40 \mathrm{~S}$ subunit binding or scanning, or indirectly, by acting as receptors for a regulatory RNA-binding protein. 


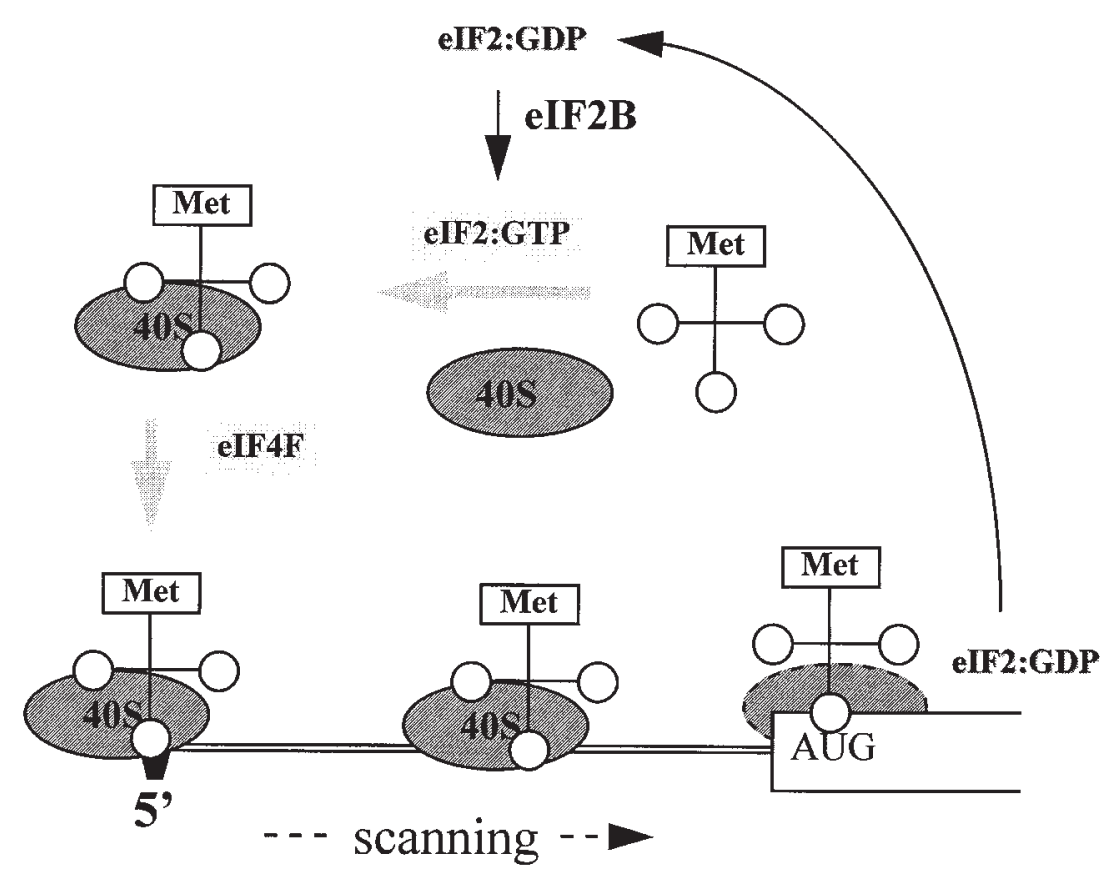

Figure 3 The initiation of translation on eukaryotic mRNAs, identifying the steps at which either global or mRNA-specific regulation is exerted. See text for a full explanation.

\section{Regulation of eIF2 activity}

The initiation factor eIF2 has a critical role in translational control (Fig. 3). This factor functions to recruit the initiator Met-tRNA ${ }_{i}$, as a Met-tRNA - eIF2-GTP ternary complex, to the $43 \mathrm{~S}$ ribosomal complex, which in turn consists of the $40 \mathrm{~S}$ ribosomal subunit and two other translation initiation factors, eIF3 and eIF4C. The guanine nucleotide exchange factor, eIF2B, catalyses the conversion of eIF2-GDP (which is inactive in translation) to eIF2-GTP in order for eIF2 to be recycled into the initiation process (Goss et al. 1984). In mammals, phosphorylation of the $\alpha$-subunit of eIF2 on Ser51 is induced in response to a number of different stress conditions including iron (haem) deprivation and heat-shock in reticulocytes, viral infection and interferon treatment in humans and mice. The kinase responsible for this phosphorylation is either haem-controlled repressor (HCR; Chen et al. 1991) or protein kinase activated by double-stranded RNA (PKR, also known as double-stranded RNAactivated inhibitor, DAI; Meurs et al. 1990). Phosphorylation of eIF2 $\alpha$ inhibits guanine nucleotide exchange on eIF2 because the eIF2 $(\alpha \mathrm{P})-$ GDP complex has an increased affinity for eIF2B, thus preventing it from catalysing the exchange of GDP for GTP. This results in a decrease in the amount of eIF2B available to recycle the remaining non-phosphorylated eIF2-GDP and leads to a downregulation of general protein synthesis in cells under various stresses.
Direct regulation of eIF2B activity, independent of changes in eIF2 phosphorylation, can also regulate eIF2 activity and thus translation. A well characterised example involves Chinese Hamster Ovary (CHO) cells overexpressing the insulin receptor, in which insulin increases the eIF2B activity by down-regulating an inhibitory activity (Welsh \& Proud 1992, 1993). The inhibitor is believed to be glycogen synthase kinase-3 (GSK-3), which phosphorylates the largest subunit of eIF2B.

\section{Regulation of eIF4E activity}

The cap-binding translation factor, eIF4E, is a key component of the eIF4F cap-binding complex that binds directly to the $\mathrm{m}^{7} \mathrm{G}$ cap structure at the $5^{\prime}$ end of a eukaryotic mRNA to facilitate $43 \mathrm{~S}$ complex binding to the mRNA (Fig. 3). Regulation of eIF4E activity in mammalian cells can be regulated in one of three ways:

(i) Cellular concentrations of eIF4E may be the limiting factor compared with other initiation factors and ribosomal subunits (Hiremath et al. 1985, Duncan et al. 1987). However, recent evidence suggests that the levels of eIF4E may be higher than had previously been reported; for example, the rabbit reticulocyte lysate contains a functional excess of eIF4E (Rau et al. 1996).

(ii) eIF4E is a phosphoprotein and the phosphorylated form of mammalian eIF4E has a three- to fourfold greater affinity both for the cap structure (Minich et al. 1994) and 
for eIF4G, compared with the non-phosphorylated form of eIF4E (Goss 1987). eIF4E is phosphorylated in response to hormones (Morley \& Traugh 1990, Flynn \& Proud 1996) and growth factors (Bu \& Hagedorn 1991, Donaldson et al. 1991), but becomes dephosphorylated following heat-shock (Duncan et al. 1987, Lamphear \& Panniers 1990) and viral infection (Huang \& Schneider 1991, Kleijn et al. 1996). Changes in the phosphorylation state of eIF4E mediate changes in overall rates of protein synthesis and recruitment of individual transcripts that differ in their dependence on eIF4E. For example, HSP mRNAs are efficiently translated in HeLa cells deficient in both eIF4E and eIF4G (Joshi-Barve et al. 1992). The phosphorylation site of mammalian eIF4E is Ser209 (Joshi et al. 1995). Although eIF4E can be phosphorylated in vitro by protein kinase $\mathrm{C}$ (PKC), multiple signal transduction pathways appear to be involved, at least in mammalian cells (Flynn \& Proud 1996). In contrast, the major phosphorylation sites of yeast eIF4E are Ser2 and Ser15, and these sites can be phosphorylated in vitro by caesin kinase II (Zanchin \& McCarthy 1995). Furthermore, only a small fraction of yeast eIF4E is phosphorylated in vivo and this level appears to be unaffected by heat-shock (Zanchin \& McCarthy 1995). The regulation of eIF4E activity in yeast therefore appears to be less dependent upon its phosphorylation state than is mammalian eIF4E.

(iii) Two translational repressors, the eIF4E-binding proteins, 4E-BP1 (also known as phosphorylated heat- and acid-stable protein, insulin stimulated: PHAS-I) and 4EBP2, regulate eIF4E function (Pause et al. 1994). They inhibit eIF4E function by competing with eIF4G for a binding site on eIF4E (Mader et al. 1995, Haghighat et al. 1995) and their binding to eIF4E is also regulated by phosphorylation; for example, 4E-BP1 becomes hyperphosphorylated in cells after treatment with hormones or growth factors, and subsequently dissociates from eIF4E (Pause et al. 1994, Lin et al. 1994). However, 4E-BP1 is dephosphorylated upon infection with encephalomyocarditis virus (EMCV) and poliovirus, enabling it to bind to eIF4E (Gingras et al. 1996). When 4E-BP1 is bound to eIF4E, phosphorylation by $\mathrm{PKC}$ is prevented. Therefore, eIF4E phosphorylation may require the action of two kinases, one to phosphorylate 4E-BPs to free the eIF4E, and then PKC to phosphorylate it (Whalen et al. 1996). A model for one pathway leading to eIF4E phosphorylation in mammalian cells is illustrated in Fig. 4.

In yeast, eIF4E is associated with a second protein (p20), which in turn is a repressor of cap-dependent translation initiation (Altmann et al. 1997). In common with mammalian 4E-BP1, p20 competes with eIF4G for binding to eIF4E (Altmann et al. 1997). p20 can be phosphorylated by caesin kinase II in vitro, putative sites of phosphorylation being Ser91, Ser154, or both, and the amount of phosphorylated p20 found associated with eIF4E increases during a heat-shock, but decreases during stationary phase (Zanchin \& McCarthy 1995). Thus, the activity of p20

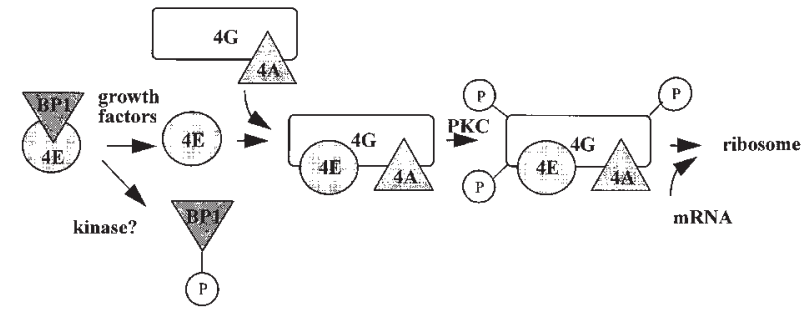

Figure 4 Regulation of elF4E function in mammalian cells. 4E-BP1 becomes hyperphosphorylated by hormones or growth factors and subsequently dissociates from elF4E. This, in turn, enables elF4E to bind to elF4G and to become phosphorylated by PKC. The phosphorylated elF4E-elF4G complex is now able to bind to the 5' cap structure (Whalen et al. 1996).

appears to be modulated by phosphorylation in a manner analogous to that of the mammalian eIF4E-BPs. p20 and eIF4E-BPs show little amino acid sequence similarity.

\section{Control of $m R N A$ translation by the $5^{\prime} U T R$}

Structural features of the $5^{\prime}$ UTR of an mRNA can be important in controlling the level of translation initiation occurring on that transcript. These include:

(i) The presence of an $m^{7} G$ cap structure. The $5^{\prime}$ cap structure is on all known eukaryotic mRNAs (except for organellar mRNAs) and most viral mRNAs (the exceptions being animal picornaviruses and plant retroviruses). This structure consists of a methylguanosine that is attached to the $5^{\prime}$ end of the mRNA via a $5^{\prime}-5^{\prime}$ triphosphate linkage and is denoted $\mathrm{m}^{7} \mathrm{G}\left(5^{\prime}\right) \mathrm{ppp}\left(5^{\prime}\right) \mathrm{N}$ (where $\mathrm{N}$ represents the first nucleotide), or simply as $\mathrm{m}^{7} \mathrm{G}$. In yeast, only two types of cap structure are known, namely $\mathrm{m}^{7} \mathrm{GpppA}$ and $\mathrm{m}^{7} \mathrm{GpppG}$ (Spirati et al. 1976). The $\mathrm{m}^{7} \mathrm{G}$ cap structure protects mRNAs from $5^{\prime} \rightarrow 3^{\prime}$ exonucleolytic degradation (Furuichi et al. 1977) and stimulates translational efficiency (Shatkin 1976). A non-methylated cap will not stimulate translation, although it still stabilises the mRNA (Horikami et al. 1984). However, mRNAs with long, unstructured leader sequences are less dependent on this cap structure, as demonstrated in vertebrates (Kozak 1991a), plants (Gallie et al. 1989) and yeast (Gerstel et al. 1992).

(ii) The primary sequence context of the initiation codon. The efficiency with which the $43 \mathrm{~S}$ preinitiation complex recognises the AUG codon as the start of initiation is dependent on the nucleotides surrounding that codon (Kozak 1986). A statistical analysis of the sequences surrounding initiator AUGs in eukaryotic mRNAs (Kozak 1986), identified (A/G)CCAUGG as the optimal sequence, although this was derived mainly from vertebrate mRNAs. More recent work has shown considerable variation between eukaryotic groups, but they all share a preference for purines at the -3 position (including yeast; Baim \& Sherman 1988) and the identity of this nucleotide 
appears to be of functional importance for efficient AUG selection (reviewed by Cavener \& Ray 1991). Positions +5 and +6 also appear to be important determinants for initiation, particularly at non-AUG codons such as GUG and CUG (Boeck \& Kolakofsky 1994, Grünert \& Jackson 1994).

(iii) The presence of upstream AUGs. Generally, the eukaryotic $43 \mathrm{~S}$ preinitiation complex initiates translation at the most 5' proximal AUG codon (Kozak 1987). However, exceptions to this 'first-AUG counts' rule do occur in vertebrates, as a result of reinitiation or leaky $43 \mathrm{~S}$ complex scanning. Reinitiation can occur at a downstream AUG codon when the $5^{\prime}$ AUG codon is followed closely by a termination codon (Kozak 1987, 1995); leaky scanning results when the first AUG codon is located in a suboptimal context such that some $43 \mathrm{~S}$ complexes bypass this $5^{\prime}$ AUG and initiate at a downstream AUG (Kozak 1989a). Recognition of the first AUG can be impaired when it is located close to the cap structure (Kozak 1991b), whereas the presence of upstream out-of-frame AUGs in the 5' UTRs of higher eukaryotic mRNAs tends to be inhibitory to translation (Kozak 1989b). However, these inhibitory effects can be reduced by the presence of a termination codon that is in-frame with the upstream AUG codon (uAUG) such that reinitiation can occur. The frequency of reinitiation is greater with increasing distances between the $5^{\prime}$ and $3^{\prime}$ cistrons (Kozak 1987).

The first-AUG counts rule also applies to the majority of yeast mRNAs. However, a subset of yeast mRNAs $(<5 \%)$ have upstream out-of-frame AUGs that do not correspond to sites of translation initiation. They are not continuous with the downstream open reading frame (ORF), prevent initiation at a downstream AUG codon, and are inhibitory to translation. The inhibitory effect of these uAUGs is greater when they are located closer to the authentic AUG codon. Furthermore, the presence of a termination codon in-frame with the uAUG does not facilitate translation in yeast (Yun et al. 1996), except in the case of GCN4 mRNA (Hinnebusch 1984, 1994), which has four short $\mathrm{uORF}$. Reinitiation of translation of GCN4 mRNA is dependent on a 10-nucleotide sequence flanking the termination codon of $\mathrm{UORF} 1$, indicating that initiation is coupled to the efficiency of termination (Grant \& Hinnebusch 1994).

(iv) The stability and position of secondary structures. RNA secondary structure positioned between the cap structure and the AUG codon can be inhibitory to translation initiation, with the extent of this inhibition depending on the thermodynamic stability and position of the structure. In vitro work, with mammalian cell lysates, has shown that a secondary structure of given stability is more inhibitory when located near the cap structure than when positioned near the AUG codon (Kozak 1989c). This suggests that such secondary structure, near the $5^{\prime}$ end, prevents the binding of the $43 \mathrm{~S}$ preinitiation complex to the cap structure, presumably by steric hindrance. When positioning of such a structure allows $43 \mathrm{~S}$ complex binding, it is its thermodynamic stability that determines whether it will inhibit scanning of the $40 \mathrm{~S}$ ribosomal subunit (Fig. 5a). Secondary structures, positioned downstream from an AUG codon, can actually enhance recognition of the preceding initiation codon. This is optimal when a stemloop structure is placed 14 nucleotides from the initiator AUG codon, thereby causing the $48 \mathrm{~S}$ complex to pause with its AUG recognition centre directly over the AUG codon (Kozak 1990). This may be important for the translation of mammalian mRNAs, which initiate translation at an AUG codon in a very weak $5^{\prime} / 3^{\prime}$ nucleotide context. Yeast $40 \mathrm{~S}$ ribosomal subunits appear to be less able to destabilise secondary structures (Baim \& Sherman 1988, Cigan et al. 1988) than are their mammalian counterpart. Furthermore, secondary structures are more inhibitory to translation in yeast when located near the initiation codon than when they are near the $5^{\prime}$ cap structure (Vega Laso et al. 1993). The reasons for these differences are unclear, but must reflect differences in the mechanism of translation between higher eukaryotes and yeast.

(v) The length of the $5^{\prime}$ leader. Progressive shortening of the 5' UTR of a eukaryotic mRNA usually promotes leaky scanning, unless there is a well-positioned downstream secondary structure. Such a structure suppresses leaky scanning, possibly by slowing the movement of the scanning $40 \mathrm{~S}$ ribosomal subunit such that it is able to recognise the first AUG codon (Kozak 1990). Lengthening the 5' UTR can lead to a proportional increase in translational efficiency (Kozak 1991a), which may simply be due to increased loading of the $40 \mathrm{~S}$ subunits on the longer $5^{\prime}$ UTRs. Seventy percent of higher eukaryotic mRNAs are 20-80 nucleotides long, with a mean length of 60 nucleotides. Similarly, $70 \%$ of yeast mRNAs have $5^{\prime}$ UTRs that are 20-60 nucleotides long, with a mean length of 52 nucleotides (Cigan \& Donahue 1987). Yeast 5' UTRs are more A-rich than their vertebrate counterparts and require at least 30 nucleotides for optimal translation (van den Heuvel et al. 1989). This may be because formation of the $80 \mathrm{~S}$ ribosome at the AUG codon on an mRNA with a short 5' UTR sterically hinders access of further $40 \mathrm{~S}$ subunits to the cap, as the diameter of the eukaryotic ribosome is approximately 30 nucleotides (Kozak \& Shatkin 1976). However, the $5^{\prime}$ UTR is not absolutely essential; for example, the yeast TCM1 mRNA, lacking its $5^{\prime}$ UTR, but possessing a cap structure at the +1 position, can be translated, albeit inefficiently (Maicas et al. 1990).

\section{The importance of non-coding sequences in controlling mRNA translation}

\section{$5^{\prime}$ UTR elements recognised by RNA-binding proteins}

In addition to setting the constitutive level of translation of a specific transcript, mRNA secondary structures 
a

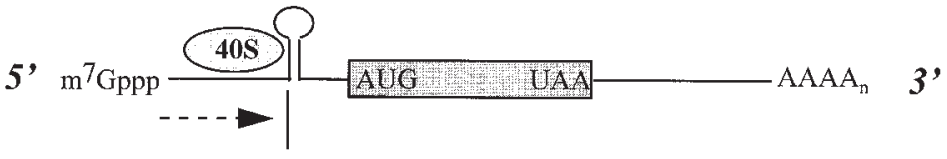

$\mathrm{b}$

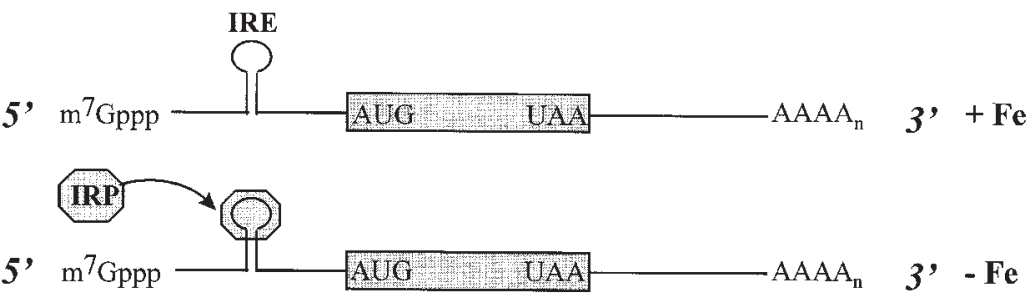

$\mathrm{C}$

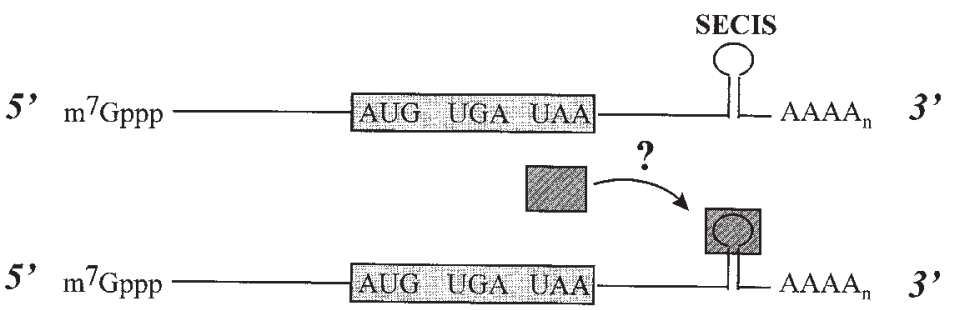

Figure 5 Regulation of translation by RNA-RNA and RNA-protein interactions. (a) Secondary structures within the $5^{\prime}$ UTR can act as a barrier to the scanning $43 \mathrm{~S}$ ribosomal complex. (b) Ferritin mRNA contains an IRE in its $5^{\prime}$ UTR to which the IRE binding protein (IRP) binds when intracellular concentrations of iron are low, and inhibits its translation. The reduced ferritin concentration leads to a decrease in iron storage. When iron concentrations are high, translation of ferritin is enhanced, resulting in enhanced iron storage. (c) The presence of the selenocysteine insertion sequence, SECIS, within the 3' UTR of a number of eukaryotic mRNAs directs insertion of selenocysteine (SelCys) at in-frame UGA codons.

can also have a regulatory role. For example, RNA structural elements can provide sites for the binding of regulatory proteins, and when such structures are located within the $5^{\prime}$ UTR they can impede binding or scanning of the $40 \mathrm{~S}$ ribosomal subunit by stabilising the structural element, which would not otherwise be inhibitory to initiation. Well-characterised examples are the erythroid 5-aminolevulinate synthase (e $A L A s)$ and ferritin mRNAs, both of which contain IREs in their $5^{\prime}$ UTRs, to which IRPs bind when intracellular iron concentrations are low (Fig. 5b). For the IRE-IRP complex to inhibit protein synthesis efficiently, the IRE must be cap-proximal (Goossen et al. 1990, Goossen \& Hentze 1992).

\section{Regulation by elements in the 3' UTR}

It is becoming increasingly clear that the $3^{\prime}$ UTR of an mRNA can have equally as important a role as has the $5^{\prime}$ UTR in regulating gene expression post-transcriptionally. In addition to the poly(A) tail, which enhances translation (reviewed by Munroe \& Jacobson 1990a), there are an increasing number of examples of other sequences within the $3^{\prime}$ UTR that regulate mRNA stability or translational efficiency, or both. Examples of translational regulation by the $3^{\prime}$ UTR include a domain within the pseudoknot in the $3^{\prime}$ UTR of the tobacco mosaic virus (TMV) RNA, which regulates translation (Gallie \& Walbot 1990, Leathers et al. 1993), interaction between an RNAbinding protein and a pyrimidine-rich motif in the $3^{\prime}$ UTR of the 15-lipoxygenase (LOX) mRNA (OstareckLederer et al. 1994), an AU-rich sequence within the $3^{\prime}$ UTR of the human cytokine mRNA, which inhibits translation (Kruys et al. 1989), the presence of the selenocysteine (SelCys) insertion sequence (SECIS) within the 3' UTR of a number of eukaryotic mRNAs, which directs insertion of (SelCys) at in-frame UGA codons (Low \& Berry 1996; Fig. 5c), and mammalian histone mRNAs, which terminate in stem-loop structures that are functionally similar to the poly(A) tail (Gallie et al. 1996). Examples in which the $3^{\prime}$ UTR functions in developmental 


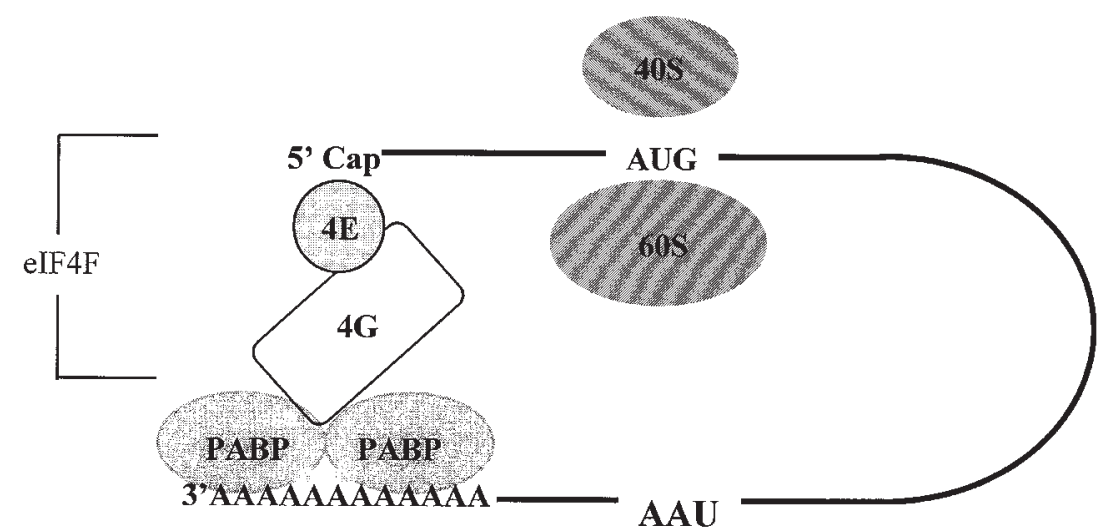

Figure 6 A model for the proposed interaction of the $5^{\prime}$ and $3^{\prime}$ ends of an mRNA by binding of PABP with elF4G. The initiation factors, elF4E and elF4G (denoted 4E and 4G respectively), may form a bridge between the 5' cap structure and one or more PABP molecules bound at the $3^{\prime}$ end of the mRNA.

regulation include Xenopus c-mos and cyclin mRNAs (Sheets et al. 1994). The mechanism(s) by which 3' UTR-mediated regulation is achieved remains to be established, but is likely to involve specific RNA-protein interactions.

\section{Regulation by $5^{\prime}-3^{\prime}$ interactions}

Recently, the role of molecular communication between the $5^{\prime}$ and $3^{\prime}$ ends of an mRNA in the regulation of translation of that mRNA has received considerable attention. It is becoming evident that there is both a physical and a functional interaction between the two ends of an mRNA. Certainly mRNAs with base complementarity between the $5^{\prime}$ and $3^{\prime}$ UTRs and which form a stable secondary structure, are translated poorly, if at all, in COS cells (Kozak 1989c) and in yeast (Vega Laso et al. 1993), although in both cases mRNA degradation is also inhibited. However, in plant mRNAs, the cap and poly(A) tail act synergistically to achieve a high translational level in vivo (Gallie 1991). This may be due to the interaction of PABP with eIF4G, eIF4E and, possibly, other initiation factors (Gallie \& Tanguay 1994), thereby allowing for more efficient cap-dependent translation.

There is an enhancing activity on translation initiation by the poly(A) tail of mRNAs in yeast (Sachs \& Davies 1989, Gerstel et al. 1992), in rabbit reticulocyte lysates and in wheat germ (Rubin \& Halim 1987), which may exert this action through the effects of its associated PABP (reviewed by Munroe \& Jacobson 1990a). The poly(A) tail appears to stimulate translation through the association of PABP with eIF4G, in which the mRNA can be circularised by the bridging interaction between eIF4G with eIF4E and PABP (Sachs \& Buratowski 1997), as illustrated in Fig. 6. The 3' poly(A) tail and the $5^{\prime}$ cap structure may share the same function in translation initiation, namely to stimulate 40S (Tarun \& Sachs 1995) or 60S, or both (Sachs \& Davis 1989) ribosomal subunit joining to the mRNA. Those mRNAs of which the translation is to some extent eIF4E-independent may be more poly(A) tail-dependent and, in turn, may be regulated by poly(A) tail length or accessibility. Evidence supporting circularised mRNAs includes electron micrographs of polysomes with interacting $5^{\prime}$ and $3^{\prime}$ ends (for example Christensen et al. 1987) and experiments showing that exogenous poly(A) is capable of working in trans to stimulate translation of capped poly(A) ${ }^{-}$mRNA (Munroe \& Jacobson 1990b).

\section{Coupling of mRNA translation and stability}

The processes of mRNA stability and translation are closely coupled rather than being separate events in space and time. Not only do the poly(A) tail and PABP protect the transcript from exonucleases attack, but they also enhance translation initiation (reviewed by Munroe \& Jacobson 1990a). The decay of many nonsensecodon-containing mRNAs requires components of the translational apparatus (reviewed by Jacobson \& Peltz 1996).

In conclusion, studies on gene regulation to date have quite rightly focused on events occurring at the level of transcription initiation. Nevertheless, the often-held assumption that this is the only level at which gene expression can be regulated is no longer tenable. As briefly reviewed above, there are a plethora of mechanisms operating post-transcriptionally (even excluding mRNA processing events that take place in the nucleus) to regulate gene expression either specifically or globally. Increasingly important is the realisation that such events are the key to the successful outcome from highly ordered developmental processes in complex organisms. 


\section{Acknowledgements}

The work on protein synthesis in the authors' laboratory has been supported by project grants from the BBSRC. D A D held a BBSRC-supported PhD studentship.

\section{References}

Altmann M, Schmitz N, Berset C \& Trachsel H 1997 A novel inhibitor of cap-dependent translation initiation in yeast: p20 competes with eIF4G for binding to eIF4E. EMBO Journal 16 $1114-1121$

Baim SB \& Sherman F 1988 mRNA structures influencing translation in the yeast Saccharomyces cerevisiae. Molecular and Cellular Biology $\mathbf{8}$ 1591-1601.

Bernstein PL, Herrick DJ, Prokipcak RD \& Ross J 1992 Control of c- $m y c$ mRNA half-life in vitro by a protein capable of binding to a coding region stability determinant. Genes and Development $\mathbf{6}$ 642-654.

Binder R, Horowitz JA, Basilion JP, Koeller DM, Klausner RD \& Harford JB 1994 Evidence that the pathway of transferrin receptor mRNA degradation involves an endonucleolytic cleavage within the $3^{\prime}$ UTR and does not involve poly(A) shortening. EMBO Journal 13 1969-1980.

Boeck R \& Kolakofsky D 1994 Positions +5 and +6 can be major determinants of the efficiency of non-AUG initiation codons for protein synthesis. EMBO Journal 13 3608-3617.

Bu X \& Hagedorn CH 1991 Platelet-derived growth factor stimulates phosphorylation of the $25 \mathrm{kDa}$ cap binding protein (eIF-4E) in human lung fibroblasts. FEBS Letters 283 219-222.

Cavener DR \& Ray SC 1991 Eukaryotic start and stop translation sites. Nucleic Acids Research 19 3185-3192.

Chen C-YA, Chen T-M \& Shyu A-B 1994 Interplay of two functionally and structurally distinct domains of the c-fos AU-rich elements specifies its mRNA-destabilizing function. Molecular and Cellular Biology 14 416-426.

Chen JJ, Throop MS, Gehrke L, Kuo I, Pal JK, Brodsky M \& London IM 1991 Cloning of the cDNA of the heme-regulated eukaryotic initiation factor $2 \alpha$ (eIF2 $\alpha$ ) kinase of rabbit reticulocyte: homology to yeast GCN2 protein kinase and human double-stranded RNA-dependent eIF2 $\alpha$ kinase. Proceedings of the National Academy of Sciences of the USA 88 7729-7733.

Christensen AK, Kahn LE \& Bourne CM 1987 Circular polysomes predominate on the rough endoplasmic reticulum of somatotropes and mammotropes in the rat anterior pituitary. American Journal of Anatomy 178 1-10.

Cigan AM \& Donahue TF 1987 Sequence and structural features associated with translational initiator regions in yeast - a review. Gene 59 1-18.

Cigan AM, Pabich EK \& Donahue TF 1988 Mutational analysis of the HIS4 translational initiator region in Saccharomyces cerevisiae. Molecular and Cellular Biology 8 2964-2975.

Dompenciel RE, Garnepudi VR \& Schoenberg DR 1995 Purification and characterization of an estrogen-regulated Xenopus liver polysomal nuclease involved in the selective destabilization of albumin mRNA. Journal of Biological Chemistry 270 6108-6118.

Donaldson RW, Hagedorn CH \& Cohen S 1991 Epidermal growth factor or okadaic acid stimulates phosphorylation of eukaryotic initiation factor 4F. Journal of Biological Chemistry 266 3162-3166.

Duncan R, Milburn SC \& Hershey JWB 1987 Regulated phosphorylation and low abundance of HeLa cell initiation factor eIF-4F suggest a role in translational control. Journal of Biological Chemistry 262 380-388.

Flynn A \& Proud CG 1996 Insulin and phorbol ester stimulate initiation factor eIF-4E phosphorylation by distinct pathways in
Chinese hamster ovary cells overexpressing the insulin receptor. European Journal of Biochemistry 236 40-47.

Furuichi Y, LaFiandra A \& Shatkin AJ 1977 5'-Terminal structure and mRNA stability. Nature $266235-239$.

Gallie DR 1991 The cap and poly(A) tail function synergistically to regulate mRNA translational efficiency. Genes and Development $\mathbf{5}$ 2108-2116.

Gallie DR \& Walbot V 1990 RNA pseudoknot domain of tobacco mosaic virus can functionally substitute for a poly(A) tail in plant and animal cells. Genes and Development 4 1149-1157.

Gallie DR \& Tanguay 1994 Poly(A) binds to initiation factors and increases cap-dependent translation in vitro. Journal of Biological Chemistry 269 17166-17173.

Gallie DR, Lucas W \& Walbot V 1989 Visualizing mRNA expression in plant protoplasts: factors influencing efficient mRNA uptake and translation. Plant Cell 1 301-311.

Gallie DR, Lewis NJ \& Marzluff WF 1996 The histone 3'-terminal stem-loop is necessary for translation in Chinese hamster ovary cells. Nucleic Acids Research 24 1954-1962.

Gerstel B, Tuite MF \& McCarthy JEG 1992 The effects of 5 '-capping, 3 '-polyadenylation and leader composition upon the translation and stability of mRNA in a cell-free extract derived from the yeast. Saccharomyces cerevisiae. Molecular Microbiology 6 2339-2348.

Gingras A-C, Svitkin YV, Belsham GJ, Pause A \& Sonenberg N 1996 Activation of the translational suppressor 4E-BP1 following infection with encephalomyocarditis virus and poliovirus. Proceedings of the National Academy of Sciences of the USA 93 5578-5583.

Goossen B, Caughman SW, Harford JB, Klausner RD \& Hentze MW 1990 Translational repression by a complex between the ironresponsive element of ferritin mRNA and its specific cytoplasmic binding protein is position-dependent in vivo. EMBO Journal 9 4127-4133.

Goossen B \& Hentze MW 1992 Position is the critical determinant for the function of the iron-responsive elements as translational regulators. Molecular and Cellular Biology 12 1959-1966.

Goss DJ 1987 A fluorescence study of the binding of eukaryotic initiation factors to messenger RNA and messenger RNA analogues. Biochemistry 26 1551-1556.

Goss DJ, Parkhurst LJ, Mehta HB, Woodley CL \& Wahba AJ 1984 Studies on the role of eukaryotic nucleotide exchange factor in polypeptide chain initiation. Journal of Biological Chemistry 259 7374-7377.

Grant CM \& Hinnebusch AG 1994 Effect of sequence content at stop codons on efficiency of reinitiation in GCN4 translational control. Molecular and Cellular Biology 14 606-618.

Grünert S \& Jackson RJ 1994 The immediate downstream codon strongly influences the efficiency of utilization of eukaryotic translation initiation codons. EMBO Journal 13 3618-3630.

Haghighat A, Mader S, Pause R \& Sonenberg N 1995 Repression of cap-dependent translation by AE-binding protein 1: competition with p220 for binding to eukaryotic initiation factor-4E. EMBO Journal 14 5701-5709.

Herrick D \& Jacobson A 1992 A coding region segment is necessary but not sufficient for rapid decay of the HIS 3 mRNA in yeast. Gene 114 35-41.

van den Heuvel JJ, Bergkamp RJM, Planta RJ \& Raué HA 1989 Effects of deletions in the $5^{\prime}$-noncoding region on the translational efficiency of phosphoglycerate kinase mRNA in yeast. Gene $\mathbf{7 9}$ 83-95.

Hinnebusch AG 1984 Evidence for translational regulation of the activator of general amino acid control in yeast. Proceedings of the National Academy of Sciences of the USA 81 6442-6446.

Hinnebusch AG 1994 Translational control of GCN4: an in vivo barometer of initiation-factor activity. Trends in Biochemical Sciences 19 409-414. 
Hiremath LS, Webb NR \& Rhoads RE 1985 Immunological detection of the messenger RNA cap-binding protein. Journal of Biological Chemistry $2607843-7849$.

Horikami SM, De Ferra F \& Moyer SA 1984 Characterization of the infections of permissive and nonpermissive cells by host range mutants of vesicular stomatitis virus defective in RNA methylation. Virology 138 1-15.

Huang J \& Schneider RJ 1991 Adenovirus inhibition of cellular protein synthesis involves inactivation of cap-binding protein. Cell 65 271-280.

Jacobson A \& Peltz SW 1996 Interrelationships of the pathways of mRNA decay and translation in eukaryotic cells. Annual Review of Biochemistry 65 693-739.

Joshi B, Cai A-L, Keiper BD, Minich WB, Mendez R, Beach CM, Stepinski J, Stolarski R, Darzynkiewicz E \& Rhoads RE 1995 Phosphorylation of eukaryotic protein synthesis initiation factor $4 \mathrm{E}$ at ser-209. Journal of Biological Chemistry 270 14597-14603.

Joshi-Barve S, De Benedetti A \& Rhoads RE 1992 Preferential translation of heat shock mRNAs in HeLa cells deficient in protein synthesis initiation factors eIF-4E and eIF-4G. Journal of Biological Chemistry $26721038-21043$.

Kleijn M, Vrins CLJ, Voorma HO, Thomas AAM 1996 Phosphorylation state of the cap-binding protein eIF4E during viral infection. Virology 217 486-494.

Kozak M 1986 Point mutations define a sequence flanking the AUG initiator codon that modulates translation by eukaryotic ribosomes. Cell 44 283-292.

Kozak M 1987 Effects of intercistronic length on the efficiency of reinitiation by eucaryotic ribosomes. Molecular and Cellular Biology 7 3438-3445.

Kozak M 1989a Context effects and inefficient initiation at non-AUG codons in eucaryotic cell-free translation systems. Molecular and Cellular Biology 9 5073-5080.

Kozak M $1989 b$ The scanning model for translation: an update. Journal of Cell Biology 108 229-241.

Kozak M 1989c Circumstances and mechanisms of initiation of translation by secondary structure in eucaryotic mRNAs. Molecular and Cellular Biology 9 5134-5142.

Kozak M 1990 Downstream secondary structure facilitates recognition of initiator codons by eukaryotic ribosomes. Proceedings of the National Academy of Sciences of the USA 87 8301-8305.

Kozak M 1991a Effects of long $5^{\prime}$ leader sequences on initiation by eukaryotic ribosomes in vitro. Gene Expression 1 117-125.

Kozak M 1991b A short leader sequence impairs the fidelity of initiation by eukaryotic ribosomes. Gene Expression 1 111-115.

Kozak M 1995 Adherance to the first-AUG rule when a second AUG codon follows closely upon the first. Proceedings of the National Academy of Sciences of the USA 92 2662-2666.

Kozak M \& Shatkin A 1976 Characterization of ribosome-protected fragments from reovirus messenger RNA. Journal of Biological Chemistry 251 4259-4266.

Kruys V, Marinx O, Shaw J, Deschamps J \& Huez G 1989 Translational blockage imposed by cytokine-derived UA-rich sequences. Science 245 852-854.

Lamphear BJ \& Panniers R 1990 Cap binding protein complex that restores protein synthesis in heat-shocked Ehrlich cell lysates contain highly phosphorylated eIF-4E. Journal of Biological Chemistry 265 5333-5336.

Leathers V, Tanguay R, Kobayashi M \& Gallie DR 1993 A phytogenetically conserved sequence within viral $3^{\prime}$ untranslated RNA pseudoknot regulates translation. Molecular and Cellular Biology 13 5331-5347.

Leeds P, Wood JM, Lee B-S \& Culbertson MR 1992 Gene products that promote mRNA turnover in Saccharomyces cerevisiae. Molecular and Cellular Biology 12 2165-2177.

Lin T-A, Kong X, Haystead TAJ, Pause A, Belsham G, Sonenberg N \& Lawrence JC 1994 PHAS-I as a link between mitogen-activated protein kinase and translation initiation. Science 266 653-656.
Low SC \& Berry MJ 1996 Knowing when to stop: selenocysteine incorporation in eukaryotes. Trends in Biochemical Sciences $\mathbf{2 1}$ 203-208.

Mader S, Lee H, Pause A \& Sonenberg N 1995 The translation initiator factor eIF-4E binds to a common motif shared by the translation factor eIF-4G and the translational repressors 4E-binding proteins. Molecular and Cellular Biology 15 4990-4997.

Maicas E, Shago M \& Friesen JD 1990 Translation of the Saccharomyces cerevisiae tcm 1 gene in the absence of a $5^{\prime}$-untranslated leader. Nucleic Acids Research 18 5823-5828.

Merrick WC \& Hershey JWB 1996 The pathway and mechanism of eukaryotic protein synthesis. In Translational Control, pp 31-70. Eds JWB Hershey, MB Matthews \& N Sonenberg. NY: Cold Spring Harbor Laboratory Press.

Meurs E, Chong K, Galabra J, Thomas NSB, Kerr IM, Williams BRG \& Hovanessian AG 1990 Molecular cloning and characterization of the human double-stranded RNA-activated protein kinase induced by interferon. Cell 63 379-390.

Minich WB, Balasta ML, Goss DJ \& Rhoads RE 1994 Chromatographic resolution of in vivo phosphorylated and nonphosphorylated eukaryotic translation initiation factor eIF-4E: increased cap affinity of the phosphorylated form. Proceedings of the National Academy of Sciences of the USA 91 7668-7672.

Morley SJ \& Traugh JA 1990 Differential stimulation of phosphorylation of initiation factors eIF-4F, eIF-4B, eIF-3 and ribosomal protein $\mathrm{S} 6$ by insulin and phorbol esters. Journal of Biological Chemistry 265 10611-10616.

Muhlrad D \& Parker R 1992 Mutations affecting stability and deadenylation of the yeast MFA2 transcript. Genes Development 6 2100-2111.

Muhlrad D \& Parker R 1994 Premature translational termination triggers mRNA decapping. Nature 340 578-581.

Munroe D \& Jacobson A 1990a Tales of poly(A): a review. Gene 91 151-158.

Munroe D \& Jacobson A 1990 b mRNA poly(A) tail, a 3' enhancer of translational initiation. Molecular and Cellular Biology 10 3441-3445.

Ostareck-Lederer A, Ostareck DH, Standart N \& Thiele BJ 1994 Translation of 15-lipoxygenase mRNA is inhibited by a protein that binds to a repeated sequence in the $3^{\prime}$ untranslated region. EMBO Journal 13 1476-1481.

Pain VM 1996 Initiation of protein synthesis in eukaryotic cells. European Journal of Biochemistry 236 747-771.

Pause A, Belsham GJ, Gingras A, Donze O, Lin T -A, Lawrence JC \& Sonenberg N 1994 Insulin-dependent stimulation of protein synthesis by phosphorylation of a regulator of $5^{\prime}$-cap function. Nature 371 763-767.

Peltz SW, Brown AH \& Jacobson A 1993 mRNA destabilization triggered by premature translational termination depends on at least three cis-acting sequence elements and one trans-acting factor. Genes and Development 7 1737-1754.

Peltz SW, Feng H, Welch E \& Jacobson A 1994 Nonsense-mediated mRNA decay in yeast. Progress in Nucleic Acids Research and Molecular Biology 47 271-298.

Pierrat B, Lacroute F \& Losson R 1993 The $5^{\prime}$ untranslated region of the PPR1 regulatory gene dictates rapid $m R N A$ decay in yeast Gene 131 43-51.

Rau M, Ohlmann T, Morley SJ \& Pain VM 1996 A reevaluation of the cap-binding protein eIF4E, as a rate-limiting factor for initiation of translation in reticulocyte lysates. Journal of Biological Chemistry $2718983-8990$

Ross J 1996 Control of messenger RNA stability in higher eukaryotes. Trends in Genetics 12 171-175.

Rubin HN \& Halim MN 1987 A direct evidence involvement of poly(A) in protein synthesis. Biochemistry and Biophysics Research Communications 144 649-656.

Sachs AB \& Davis RW 1989 The poly(A) binding protein is required for poly(A) shortening and 60 S ribosomal subunit-dependent translation initiation. Cell $\mathbf{5 8} 857-867$. 
Sachs AB \& Buratowski S 1997 Common themes in translational and transcriptional regulation. Trends in Biochemical Sciences 22 189-192.

Shatkin AJ 1976 Capping of eukaryotic mRNAs. Cell 9 645-653.

Shaw G \& Kamen R 1986 A conserved AU sequence from the 3' untranslated region of GM-CSF mRNA mediates selective mRNA degradation. Cell 46 659-667.

Sheets MD, Fox CA, Hunt T, Vande Woude G \& Wickens M 1994 The 3 '-untranslated region of c-mos and cyclin mRNAs stimulate translation by regulating cytoplasmic polyadenylation. Genes and Development 8 926-938.

Spirati CE, Groner Y \& Warner JR 1976 Methylated, blocked 5' termini of yeast mRNA. Journal of Biological Chemistry 251 2898-2904.

Stansfield I, Jones KM \& Tuite MF 1995 The end in sight: terminating translation in eukaryotes. Trends in Biochemical Sciences $20489-491$.

Tarun SZ \& Sachs AB 1995 A common function for mRNA 5' and $3^{\prime}$ ends in translation initiation in yeast. Genes and Development 9 2997-3007.

Vega Laso MR, Zhu D, Sagliocco F, Brown AJP, Tuite MF \& McCarthy JEG 1993 Inhibition of translation initiation in the yeast. Saccharomyces cerevisiae as a function of the stability and position of hairpin structures in the mRNA leader. Journal of Biological Chemistry 268 6453-6462.
Welsh GI \& Proud CG 1992 Regulation of protein synthesis in Swiss 3T3 fibroblasts. Rapid activation of the guanine-nucleotideexchange factor by insulin and growth factors. Biochemical Journal 284 19-23.

Welsh GI \& Proud CG 1993 Glycogen synthase kinase-3 is rapidly inactivated in response to insulin and phosphorylates eukaryotic initiation factor eIF-2B. Biochemical Journal 294 625-629.

Whalen SG, Gingras A, Amankwa L, Mader S, Branton PE, Aebersold R \& Sonenberg N 1996 Phosphorylation of eIF-4E on serine 209 by protein kinase $\mathrm{C}$ is inhibited by the translational repressors, 4E-binding proteins. Journal of Biological Chemistry 271 11831-11837.

Yun D, Laz TM, Clements JM \& Sherman F 1996 mRNA sequences influencing translation and the selection of AUG initiator codons in the yeast Saccharomyces cerevisiae. Molecular Microbiology 19 $1225-1239$.

Zanchin NI \& McCarthy JEG 1995 Characterization of the in vivo phosphorylation sites of the mRNA-cap-binding complex proteins eukaryotic initiation factor-4E and p20 in Saccharomyces cerevisiae. Journal of Biological Chemistry 270 1-6.

Received 11 November 1997

Accepted 2 February 1998 